\title{
Crystalline Structure and Surface Morphology of Tin Oxide Films Grown by DC Reactive Sputtering
}

\author{
Mohammad K. KHALAF, Natheera A. AL-TEMEMEE, \\ Fuad T. IBRAHIM*, and Mohammed A. HAMEED \\ Department of Physics, College of Science, University of Baghdad, Baghdad, Iraq \\ *Corresponding author: Fuad T. IBRAHIMＥ-mail: fuadtariq2002@yahoo.com
}

\begin{abstract}
Tin oxide thin films were deposited by direct current (DC) reactive sputtering at gas pressures of 0.015 mbar -0.15 mbar. The crystalline structure and surface morphology of the prepared $\mathrm{SnO}_{2}$ films were introduced by X-ray diffraction (XRD) and atomic force microscopy (AFM). These films showed preferred orientation in the (110) plane. Due to AFM micrographs, the grain size increased non-uniformly as the working gas pressure increased.
\end{abstract}

Keywords: Sputtering, reactive sputtering, thin films, tin oxide

Citation: Mohammad K. KHALAF, Natheera A. AL-TEMEMEE, Fuad T. IBRAHIM, and Mohammed A. HAMEED, "Crystalline Structure and Surface Morphology of Tin Oxide Films Grown by DC Reactive Sputtering," Photonic Sensors, 2014, 4(4): 349353.

\section{Introduction}

Tin dioxide $\left(\mathrm{SnO}_{2}\right)$ is one of the most widely used materials in thin film devices and applications, such as solar cells, photo-catalysts, gas sensors, optical coatings, and self-cleaning materials [1-3]. In general, $\mathrm{SnO}_{2}$ is very inert, surpassing glass in its resistance to attack of common solvents and acids. It acts as a catalyst for various organic reactions and, as a thin film, it is used as a dielectric for thin film capacitors and as an antireflection coated on silicon. In recent years, it has been investigated as an electrode for photoelectron chemical cells and for detectors of oxygen and hydrogen [4-8].

Reactive sputtering is widely used to prepare $\mathrm{SnO}_{2}$ thin films. Generally, high flow of the reactive gas such as oxygen is required for formation of tin compound films during reactive sputtering of tin metal. The deposition rate of the film, however, drops abruptly when compounds are formed on the target surface at high flows of the reactive gases [9]. The pressure of reactive gases, evaporation rates, and substrate temperatures are main parameters used to influence the packing density of the films, the films crystallinity, and the optical properties [10].

In this work, the structural and optical properties of $\mathrm{SnO}_{2}$ thin films prepared by the direct current (DC) reactive sputtering technique were studied at different working pressures in order to determine optimum conditions to use these $\mathrm{SnO}_{2}$ thin films as gas sensors.

\section{Experimental work}

The plasma system was made of a stainless steel cylinder (inner diameter: $30 \mathrm{~cm}$, height: $34 \mathrm{~cm}$ ), closed by stainless steel plates and sealed by o-rings. The electrodes and the metallic rods were encapsulated in the teflon shell so that only the 
electrode surfaces were in contact with the gas, and edge effects were avoided. The shells used to cover the electrodes had a circular open area of $78.5 \mathrm{~cm}^{2}$, which was the effective surface area of the electrode in contact with the gas.

The electrodes were made of stainless steel of $15 \mathrm{~mm}$ in thickness and $100 \mathrm{~mm}$ in diameter. They included an internal channel to pass the cooling water coming from and going to a digital controlled cooling system. Both electrodes were kept at constant temperature $\left(\sim 150{ }^{\circ} \mathrm{C}\right)$ to avoid the negative effects of increasing cathode temperature as well as decreasing anode temperature. Before each experiment, the electrodes were mechanically polished and chemically cleaned in dichloromethane. The pressure was controlled by a manual throttle valve mounted between the reactor and the pumping unit. The pumping system was composed of a rotary vane pump and a diffusion pump. The gas throughput was set at $150 \mathrm{~cm}^{3} / \mathrm{s}$ by a gas flow-controller. Different gases were used for the experiment with the purity of $99.99 \%$. Before each measurement, the reactor was brought to a base pressure of about $3 \times 10^{-5}$ mbar. A high voltage DC-power supply was used for delivering $3 \mathrm{kV}$ between two electrodes.

\section{Result and discussion}

Figure 1 shows the X-ray diffraction pattern for the deposited $\mathrm{SnO}_{2}$ thin films prepared by $\mathrm{DC}$ reactive sputtering on the glass substrate for different working pressures $(0.15 \mathrm{mbar}$ to $0.015 \mathrm{mbar}$ ), and at argon/oxygen mixed flow (1/2), sputtering time was $60 \mathrm{~min}$, the distance and biasing voltage between the anode and cathode were $5 \mathrm{~cm}$ and $4 \mathrm{kV}$, respectively. In all samples, randomly oriented tin oxide crystalline formation started in planes corresponding to (110), (101), (211), and (002) planes of $\mathrm{SnO}_{2}$ for $2 \theta$ values of $26.51,33.85$, 51.69 , and 57.93, respectively.

As proved by Fig. 1, the prepared films were textured, and the degree of texturing depends on the working pressure, therefore, the change in predominant orientation of crystallites formed the gas-sensitive matrix and confirmed the cassiterite structure of nanocrystalline $\mathrm{SnO}_{2}$ [11]. The (110) is the dominant crystal structure of low-index crystal faces for this material due to its stability. This is the desired structure of $\mathrm{SnO}_{2}$ for sensing applications since its prevalent (110) growth plane is extremely stable and can reject oxygen with little distortion [12]. The growth of this plane helps in achieving high oxygen vacancy concentrations at low temperature.

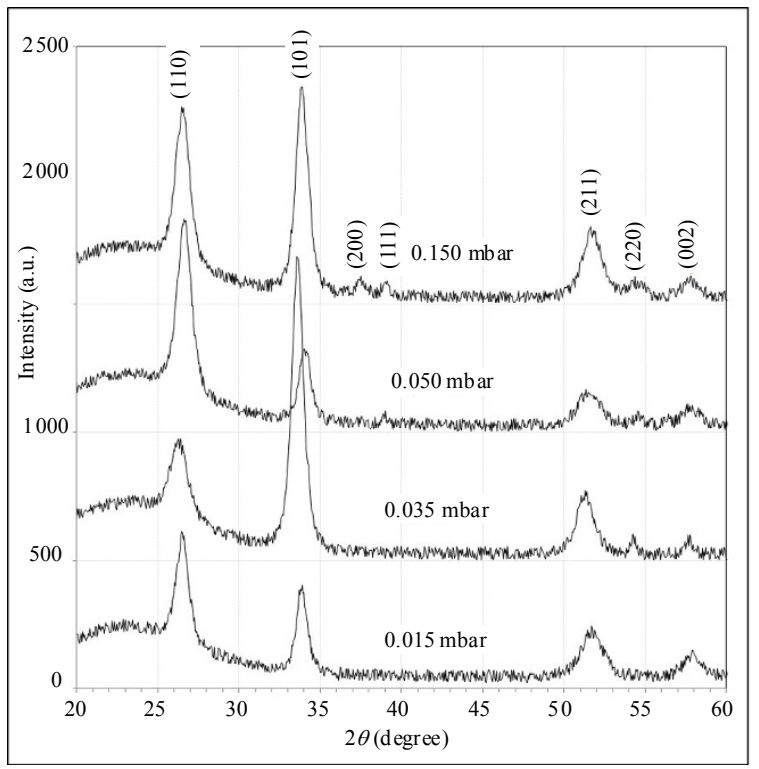

Fig. 1 XRD results of the sputtered $\mathrm{SnO}_{2}$ thin films on glass substrates at different working pressures.

Two and three-dimensional atomic force microscopy (AFM) images of the as-deposited $\mathrm{SnO}_{2}$ films at different discharge currents, working pressures, and $\mathrm{Ar} / \mathrm{O}_{2}$ flowing mixtures, are shown in Fig. 2. The average grain size (GS) and root mean square roughness (RMS) of these films are shown in Table1. The AFM images of all samples displayed are granular structure. The granular films show the higher surface area, which is conductive for film-gas interaction and results in the higher gas sensitivity [13]. The gas sensitivity has a proportional relationship with film roughness [14]. 

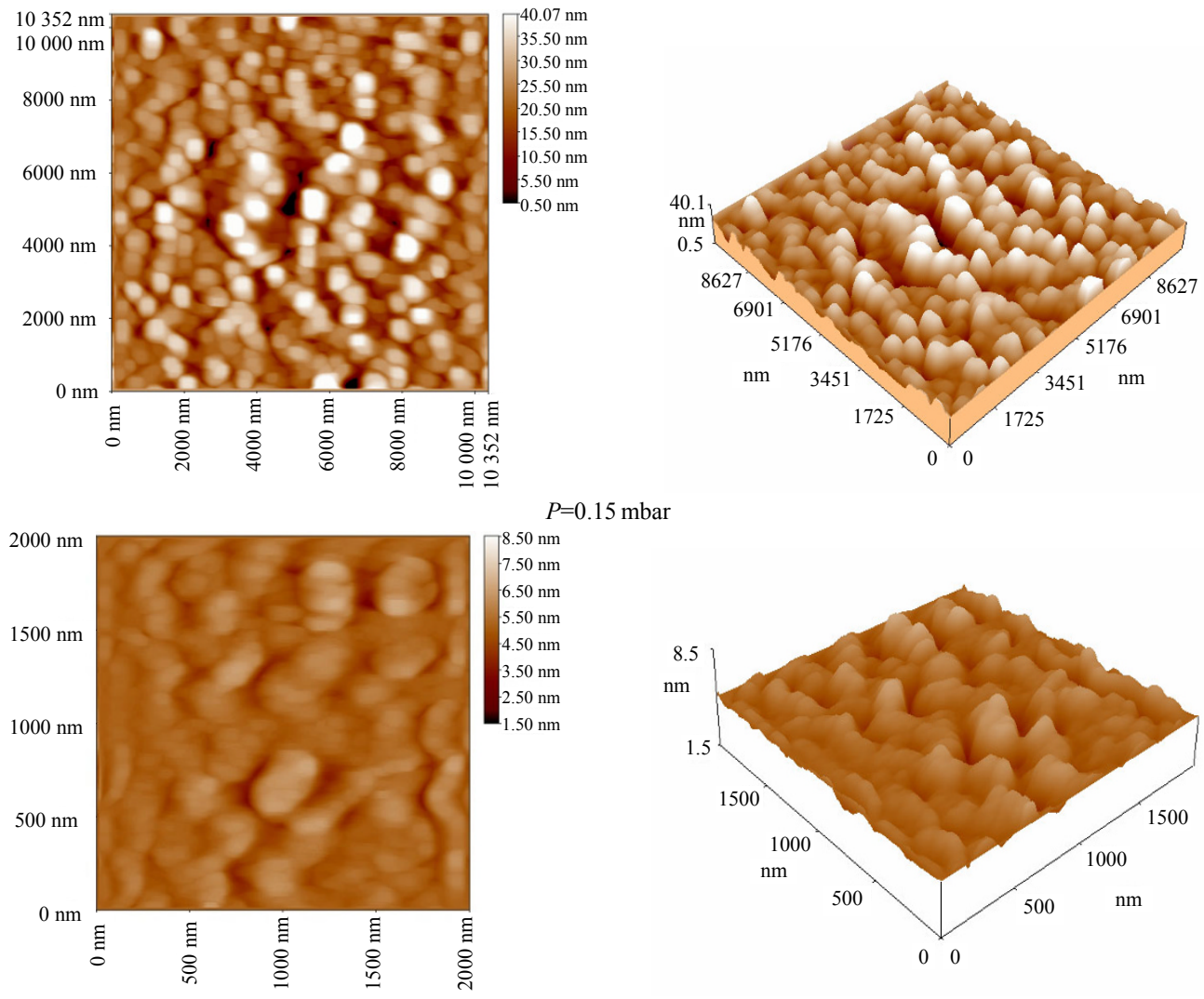

$P=0.15 \mathrm{mbar}$
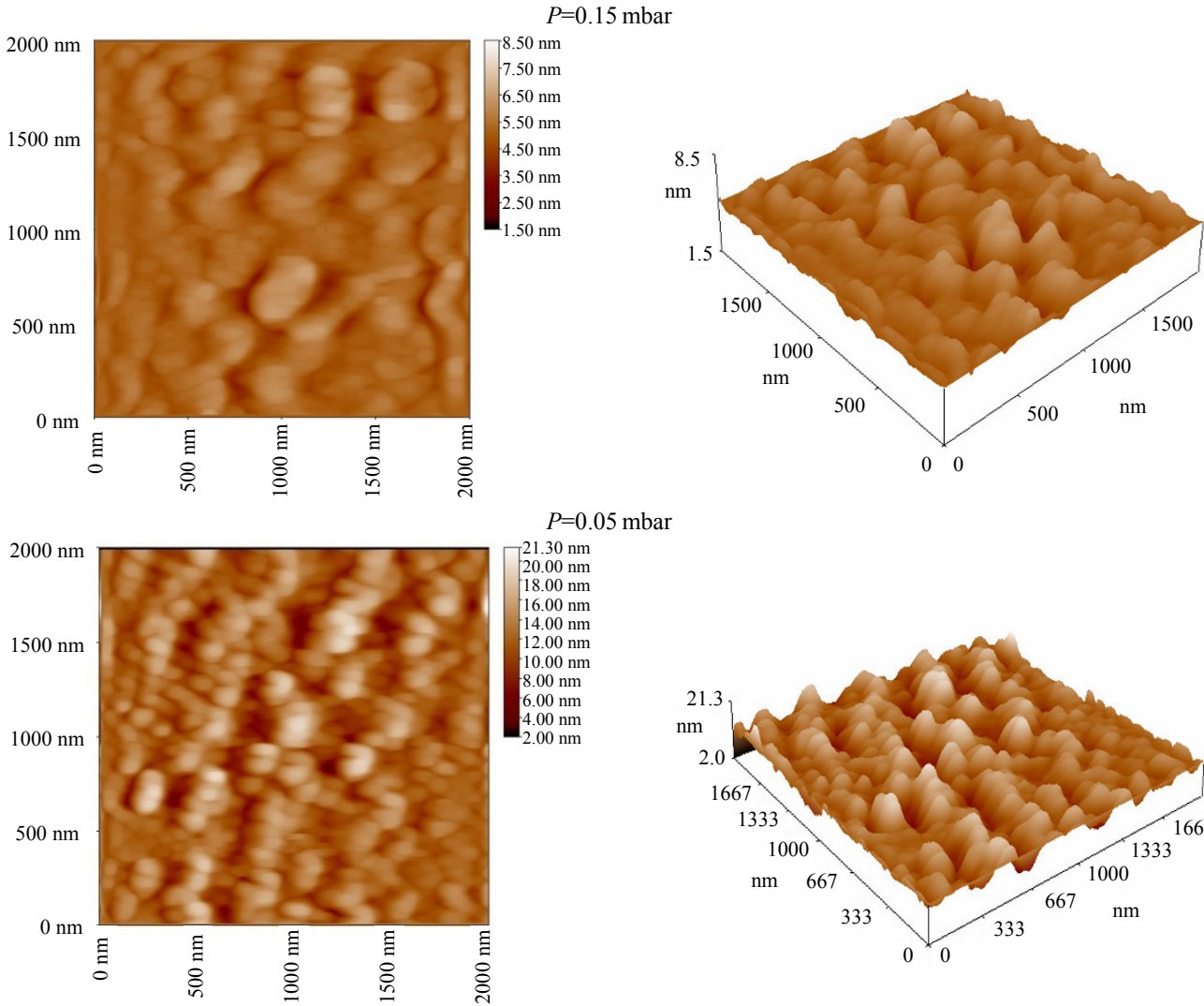

$P=0.05$ mbar

$-21.30 \mathrm{~nm}$

$18.00 \mathrm{~nm}$

$-16.00 \mathrm{~nm}$

$14.00 \mathrm{~nm}$
$12.00 \mathrm{~nm}$

$10.00 \mathrm{~nm}$

$8.00 \mathrm{~nm}$

$6.00 \mathrm{~nm}$
$4.00 \mathrm{~nm}$

$2.00 \mathrm{~nm}$
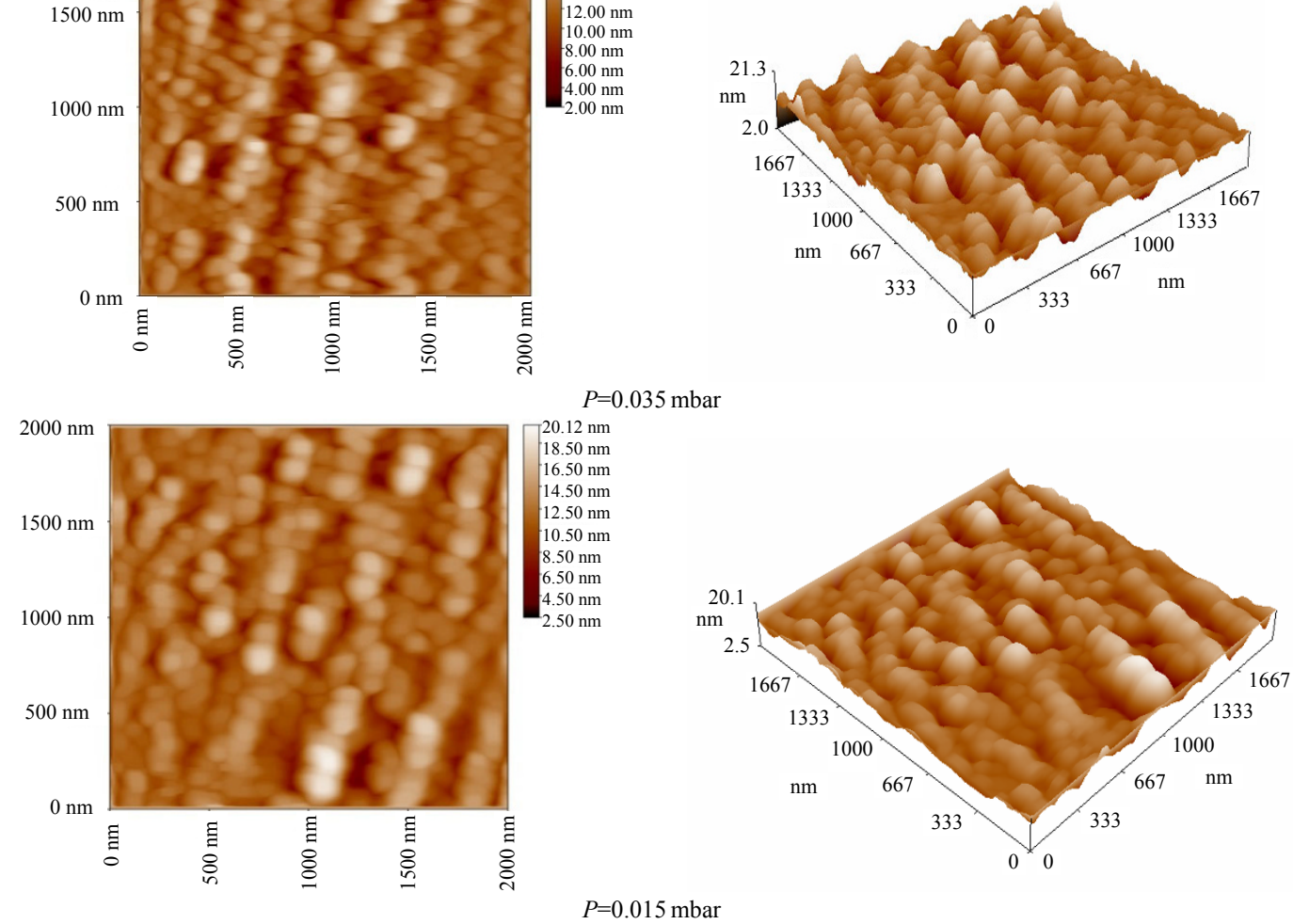

Fig. 2 AFM images of the sputtered $\mathrm{SnO}_{2}$ thin films on glass substrates at different working pressures. 
Table 1 AFM and SEM data images of $\mathrm{SnO}_{2}$ thin films deposited on the glass substrate for different conditions.

\begin{tabular}{c|c|c|c|c}
\hline $\begin{array}{c}\text { Biasing } \\
\text { voltage } \\
(\mathrm{kV})\end{array}$ & $\begin{array}{c}\text { Working } \\
\text { pressure } \\
\text { (mbar) }\end{array}$ & $\begin{array}{c}\text { Argon/Oxygen } \\
\text { mixture flow }\end{array}$ & $\begin{array}{c}\text { Average } \\
\text { roughness } \\
(\mathrm{nm})\end{array}$ & $\begin{array}{c}\text { Average } \\
\text { grain } \\
\text { size }(\mathrm{nm})\end{array}$ \\
\hline 4 & 0.15 & $1 / 2$ & 1.08 & 138.29 \\
\hline 4 & 0.05 & $1 / 2$ & 0.353 & 98.66 \\
\hline 4 & 0.035 & $1 / 2$ & 1.85 & 78.73 \\
\hline 4 & 0.015 & $1 / 2$ & 1.58 & 97.19 \\
\hline
\end{tabular}

Figure 2 shows that the grain size decreased from $138.29 \mathrm{~nm}$ at the pressure of $0.15 \mathrm{mbar}$ to $78.73 \mathrm{~nm}$ at the pressure of 0.035 mbar. At pressures lower than $0.035 \mathrm{mbar}$, the grain size increased. The roughness increased from $1.08 \mathrm{~nm}$ at $0.15 \mathrm{mbar}$ to $1.85 \mathrm{~nm}$ at $0.035 \mathrm{mbar}$ and decreased after that. The low-density plasma did not provide enough energy for the grains for renucleation that led to an increase in the average roughness and a decrease in the grain size.

From the absorption edge shown in Fig. 3, one can determine the optical energy gap, as shown in Table2. The value of the optical energy gap changed as the working pressure did for all samples and increased as the ratio of argon to oxygen did, as shown in Fig. 3 and Table 2. The relatively small value of the band gap can be attributed to the high degree of non-stoichiometric disorders in the film. This indicates that the high conducting electron density is caused by deviations from the ideal single crystal structure, i.e., oxygen vacancies, interstitial atoms, and dislocations acting as conducting electron donors [18].

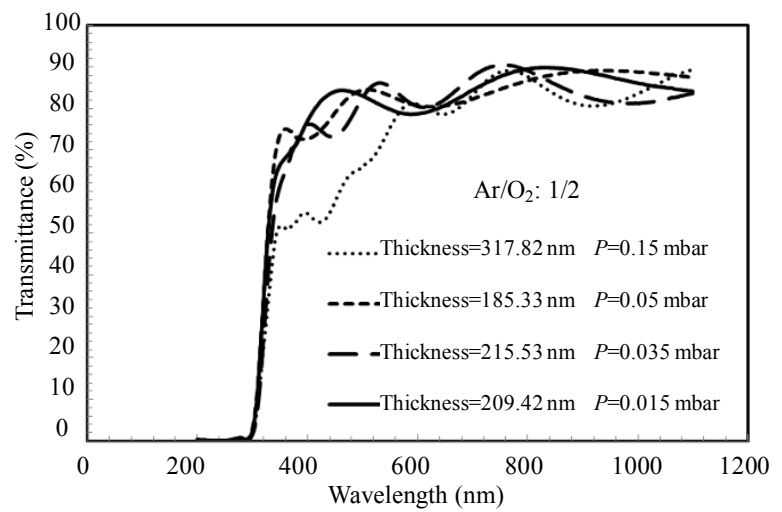

Fig. 3 Transmission spectra of the sputtered $\mathrm{SnO}_{2}$ films at different working pressures.
Table 2 Parameters of $\mathrm{SnO}_{2}$ films prepared at different sputtering working pressures and different $\mathrm{Ar} / \mathrm{O}_{2}$ mixing ratios.

\begin{tabular}{c|c|c|c}
\hline $\mathrm{Ar} / \mathrm{O}_{2}$ & $\begin{array}{c}\text { Pressure } \\
(\mathrm{mbar})\end{array}$ & $\begin{array}{c}\text { Thickness } \\
(\mathrm{nm})\end{array}$ & $E_{g}(\mathrm{eV})$ \\
\hline $1 / 2$ & 0.15 & 317.82 & 4.0 \\
\hline $1 / 2$ & 0.05 & 185.33 & 3.94 \\
\hline $1 / 2$ & 0.035 & 215.53 & 3.92 \\
\hline $1 / 2$ & 0.015 & 209.42 & 3.96 \\
\hline
\end{tabular}

The transmission spectra of $\mathrm{SnO}_{2}$ thin films are shown in Fig. 3 as functions of the wavelength ranging in the region of $200 \mathrm{~nm}-1100 \mathrm{~nm}$. The presence of oscillations in these spectra was indicative of the good optical quality of the prepared films as they all were transparent, uniform, adherent to the substrate, and stable when kept in atmosphere for a long time. The average transmission of the $\mathrm{SnO}_{2}$ films deposited on glass substrates was more than $80 \%$ over the range $400 \mathrm{~nm}-800 \mathrm{~nm}$ and was in good agreement with the published studies [15]. A sharp fall in transmission at about $310 \mathrm{~nm}$ was due to the absorption edge of $\mathrm{SnO}_{2}$ semiconducting films. The transparency of these films decreased in major portions of the visible range with the built-up thickness which was also clear from the fringes in the transmission spectra. The absorption edge also was shifted slightly to higher wavelengths with increasing the applied pressure as shown in Fig. 3. The transmittance rapidly fell in the shortwavelength region as the film thickness increased, and the onset of the absorption edge became less sharp. This might be attributed to the presence of larger crystalline sizes and increased scattering due to surface roughness $[16,17]$.

The transmission increased in the non-symmetrical way with decreasing the pressure because more atoms deposited on the film, so more crystals and states would be available for the photons to be absorbed, as could be concluded from Fig. 3.

\section{Conclusions}

Tin oxide films were prepared by the DC reactive sputtering technique. The properties of the 
prepared films were highly affected by the working gas pressure. High-quality and uniform nanocrystalline films were obtained at the working gas pressure of $0.035 \mathrm{mbar}$ and the gas mixture $\left(\mathrm{Ar} / \mathrm{O}_{2}\right)$ of 0.5 mbar. Results showed that the structure of $\mathrm{SnO}_{2}$ films was polycrystalline with the tetragonal structure (rutile) with the preferential orientation in the (110) direction. As well, the results showed that $\mathrm{SnO}_{2}$ surfaces were homogenous with columnar structures and the AFM analysis revealed porous morphology of spherical particles. From optical measurements, the transmission of the prepared films increased with a decrease in the gas pressure, and the optical transition was direct.

Open Access This article is distributed under the terms of the Creative Commons Attribution License which permits any use, distribution, and reproduction in any medium, provided the original author(s) and source are credited.

\section{References}

[1]C. Garzella, E. Comini, E. Tempesti, C. Frigeri, and G. Sberveglieri, " $\mathrm{TiO}_{2}$ thin films by a novel sol-gel processing for gas sensor applications," Sensors and Actuators B: Chemical, 2000, 68(1-3): 189-196.

[2] S. R. Kurtz and R. G. Gordon, "Chemical vapour deposition of doped $\mathrm{TiO}_{2}$ films," Thin Solid Films, 1987, 147: 167-176.

[3] I. Parkin and R. G. Palgrave, "Self-cleaning coatings," Journal of Materials Chemistry, 2005, 15(17): 1689-1695.

[4] T. Bak, J. Nowotny, M. Rekas, and C. C. Sorrell, "Photo-electrochemical hydrogen generation from water using solar energy. materials-related aspects," International Journal of Hydrogen Energy, 2002, 27(10): 991-1022.

[5] T. Bak, J. Nowotny, M. Rekas, and C. C. Sorrell, "Photo-electrochemical properties of the $\mathrm{TiO}_{2}-\mathrm{Pt}$ system in aqueous solutions," International Journal of Hydrogen Energy, 2002, 27(1): 19-26.

[6] J. Nowotny, C. C. Sorrell, L. R. Sheppard, and T. Bak, "Solar-hydrogen: environmentally safe fuel for the future," International Journal of Hydrogen Energy, 2005, 30(5): 521-544.

[7] L. Francioso, D. S. Presicce, P. Siciliano, and A.
Ficarella, "Combustion conditions discrimination properties of Pt-doped $\mathrm{TiO}_{2}$ thin film oxygen sensor," Sensors and Actuators B: Chemical, 2007, 123(1): 516-521.

[8] Y. Shimizu, N. Kuwano, T. Hyodo, and M. Egashira, "High $\mathrm{H}_{2}$ sensing performance of anodically oxidized $\mathrm{TiO}_{2}$ film contacted with Pd," Sensors and Actuators B: Chemical, 2002, 83(1-3): 195-201.

[9] S. Kadlec and J. Musil, "Low pressure magnetron sputtering and self sputtering discharges," Vacuum, 1996, 47(3): 307-311.

[10]J. Musil, A. Rajsky, A. J. Bell, J. Matous, M. Cepera, and J. Zeman, "High rate magnetron sputtering," Journal of Vacuum Science and Technology, 1996, 14(4): 2187-2191.

[11] G. Korotcenkov, J. Schwank, M. Dibattista, and V. Brinzari, "Peculiarities of $\mathrm{SnO}_{2}$ thin film deposition by spray pyrolysis for gas sensor application," Sensors and Actuators B, 2001, 77(1-2): 244-252.

[12]F. R. Sensato, R. Custodio, M. Calatayud, A. Beltran, J. Andres, J. Sambrano, et al., "Periodic study on the structural and electronic properties of bulk oxidized and reduced $\mathrm{SnO}_{2}$ (110) surfaces and the interaction with $\mathrm{O}_{2}$," Surface Science, 2002, 511(1-3): 408-420.

[13] S. C. Gadkari, T. J. Shinde, and P. N. Vasambekar, "Effect of $\mathrm{Sm}^{3+}$ ion addition on gas sensing properties of $\mathrm{Mg}_{1-x} \mathrm{Cd}_{x} \mathrm{Fe}_{2} \mathrm{O}_{4}$ system," Sensors and Actuators B, 2013, 178 (1): 34-39.

[14] N. G. Deshpandea, Y. G. Gudagea, R. Sharmaa, J. C. Vyasb, J. B. Kim, and Y. P. Lee, "Studies on tin oxide-intercalated polyaniline nanocomposite for ammonia gas sensing applications," Sensor and Actuators B, 2009, 138(1): 76-84.

[15] S. Chacko, N. Sajeeth, and V. K. Vaidyan, "Effect of substrate temperature on structural, optical and electrical properties of spray pyrolytically grown nanocrystalline $\mathrm{SnO}_{2}$ thin films," Physica Status Solidi (A) Applications and Materials, 2007, 204(10): 3305-3315.

[16] P. P. Sahay, S. Tewari, and R. K. Nath, "Optical and electrical studies on spray deposited $\mathrm{ZnO}$ thin films," Crystal Research and Technology, 2007, 42(7): 723-729.

[17] S. Ray and P. S. Gurdeep Singh, "Electrical and optical properties of sol-gel prepared Pd-doped $\mathrm{SnO}_{2}$ thin films," Journal Ovonic Research, 2010, 6(1): 23-34.

[18] M. F. Kotkata, F. A. Abdel-Wahab, and M. S. Al-Kotb, "Effect of in-content on the optical properties of a Se films," Applied Surface Science, 2008, 255: 9071-9077. 